\title{
The Long-term Effects of Percutaneous Laser Disc Decompression (PLDD) Treatment on Lumbar Disc Protrusion: A 2-Year Follow-up
}

\author{
Masoud Hashemi ${ }^{1}$, Mani Falsafi' ${ }^{2}$, Mohammad Reza Razzaghi ${ }^{3}$, Payman Dadkhah ${ }^{1}$, Mehrdad Taheri ${ }^{1}$, \\ Mohammad Hossein Delshad ${ }^{3 *}$, Alireza Zali ${ }^{4}$ \\ ${ }^{1}$ Anesthesiology Research Center, Shahid Beheshti University of Medical Sciences, Tehran, Iran \\ ${ }^{2}$ Assistant Professor of Orthopaedics, Department of Surgery, School of Medicine Shahid Beheshti Hospital, Babol University \\ of Medical Sciences, Tehran, Iran \\ ${ }^{3}$ Laser Application in Medical Sciences Research Center (LAMSRC), Shahid Beheshti University of Medical Sciences, Tehran, \\ Iran \\ ${ }^{4}$ Research Center for Neurosurgery and Functional Nerves, Shahid Beheshti University of Medical Sciences, Shohad-a-Tajrish \\ Hospital, Tehran, Iran
}

\section{*Correspondence to Mohammad Hossein Delshad, Laser Application in Medical Sciences Research Center (LAMSRC), Shahid Beheshti University of Medical Sciences, Tehran, Iran \\ Email: m.delshad@abzums.ac.ir}

Published online October 3, 2020

\begin{abstract}
Introduction: Nowadays many physicians have focused their attention on using low invasive methods for the treatment of disc protrusion. Thus, the current study was carried out to evaluate the effect and therapeutic outcomes of clinical percutaneous laser disc decompression (PLDD) in the treatment of chronic low back pain caused by disc protrusion during a two-year follow-up.

Methods: This historical cohort study was conducted on 40 patients, who were suffering from chronic low back pain caused by disc protrusion diagnosed, and referred to the pain clinic of Akhtar Hospital from March to August 2016 were treated with PLDD and were followed up for at least two years after performing PLDD (from 2018 to 2019). All the information has been extracted using medical records and patient interview. The severity of pain was measured by the Numeric Rating Scale (NRS), and the Oswestry disability index (ODI) was measured before and two years after the treatment.

Results: The most common sites for two-level PLDD were L4-S1 and L3-L5, and the most common sites for one-level PLDD were L5-S1 and L4-L5. Overall, the levels of pain and functional disability two years after PLDD showed significant improvements $(P=0.0001)$. The results revealed no statistically significant differences in NRS and ODI scores between the two groups of men and women two years after PLDD $(P>0.05)$. Furthermore, they indicated no statistically significant differences in NRS and ODI scores between the different disc protrusion levels two years after $\operatorname{PLDD}(P>0.05)$.

Conclusion: It seems that the PLDD is a low-invasive, safe, and effective method that can be used in patients with chronic low back pain caused by a disc protrusion. Therefore, it can be considered as a suitable choice in treating patients with chronic low back pain caused by a disc protrusion. Keywords: Percutaneous laser disc decompression, Disc protrusion, Chronic low back pain.
\end{abstract}

\section{Introduction}

Although disc protrusion is prevalent in the elderly, it may also occur in young people. The annulus fibrosis remains intact in disc protrusion; however, outpouching and extending the disc beyond the intervertebral space can cause pain and inflammation by pressuring the spinal nerves. While, in some patients, the symptoms of disc protrusion continue without interrupting their daily lives, severe and dangerous consequences may occur in others. Such consequences are created by leg, thigh, lumbar, and hip pain and having difficulty walking short distances. The sensation decreases in one of the legs with sciatic nerve involvement. Stinging pain from the upper back to the stomach or chest, muscle spasm even due to nerve pressure caused by disc protrusion, and bladder incontinence may develop as other symptoms of the disease. However, low back pain develops in most patients. This disease is caused by a person's lifestyle, physical activity, smoking, and the natural aging process. These patients can be treated by physiotherapy, lumbar stretching exercises, non-surgical treatments, and anti-inflammatory drugs before herniation. The conventional surgical procedure is a gold standard in surgical interventions used to treat sciatica and disc problems in these patients.

Please cite this article as follows: Hashemi M, Falsafi M, Razzaghi MR, Dadkhah P, Taheri M, Delshad MH, et al. The long-term effects of Percutaneous laser disc decompression (PLDD) treatment on lumbar disc protrusion: a 2-year follow-up. J Lasers Med Sci. 2020;11(4):427432. doi:10.34172/jlms.2020.67. 
Nowadays because of our increased knowledge of spinal anatomy, patient dissatisfaction with open surgical outcomes, and advances in imaging techniques, using low invasive methods for the treatment of disc protrusion has attracted many physicians' attention. ${ }^{1}$ Procedures used in patients with low back pain include prolotherapy, corticosteroid injection in the facet joint, medial branch block, intrathecal corticosteroid injection, radiofrequency denervation, intradiscal electrothermal therapy, epidural steroid injection, trigger point injection, adhesiolysis, nucleoplasty, percutaneous laser disc decompression (PLDD), ${ }^{2,3}$ and intravenous laser blood irradiation. ${ }^{4}$ PLDD has been described to treat radicular pain caused by disc herniation for over 20 years. ${ }^{5}$

Creating a negative pressure in the intervertebral disc by removing tissue is among the techniques used to relieve nerve root pressure. There are various skin techniques, one of which is PLDD. In this technique, laser energy is transmitted through the fiber to the nucleus pulposus. ${ }^{6}$

This fiber is inserted by a thin needle under local anesthesia using the percutaneous posterolateral approach. The absorption of the applied laser energy results in the evaporation of the water content of the nucleus pulposus and leads to changes in its protein structure. Therefore, subsequent volume depletion reduces disproportionate pressure on the disk and relieves the nerve root. Clinical PLDD was first performed by Choy and Ascher in Europe in $1986 .{ }^{7}$ In 1991, the FDA approved the use of PLDD in the United States. ${ }^{8}$

PLDD is a good alternative to conventional surgery because it is low invasive and reduces the risk of damage to muscles, bones, ligaments, and nerves. Although the symptoms improve almost immediately after performing the conventional surgery, the actual sciatica recovery takes a long time. But, the patients have to deal with less severe low back pain, shorter hospitalization, and shorter recovery time after PLDD compared to the conventional method. In cohort studies, the safety and advantages of applying PLDD have been shown. ${ }^{9}$

A study indicated that PLDD, as a minimally invasive method, reduces pain and disability in patients with lumbar disc herniation. ${ }^{10}$

PLDD is one of the low invasive therapeutic interventions in patients with disc protrusion. This is a skin treatment; hence, its morbidity is lower and its recovery is faster than the conventional surgery. Moreover, patients can return to work a few days after the surgery. Despite controversies, PLDD is still widely regarded by many physicians; however, further research is still needed for clinical certainty.

Accordingly, the current study examined the effect and therapeutic outcomes of PLDD in the treatment of chronic low back pain caused by disc protrusion and the improvement of pain severity and functional disability during a two-year follow-up.

\section{Materials and Methods}

Sampling Method

Forty-three patients, 3 of whom could not be reached, were selected sequentially using the simple non-random sampling method; therefore, a medical record of 40 patients was studied.

\section{Methods}

This historical cohort study was performed after being approved by the Ethics Committee of Shahid Beheshti University of Medical Sciences (IR.SBMU.RETECH. REC.1397.1328). In this regard, 40 patients who were suffering from chronic low back pain caused by disc protrusion diagnosed based on clinical examinations and MRI/CT scan findings and referred to the pain clinic of Akhtar Hospital from March to August 2016 were treated with PLDD and were followed up for at least two years after performing PLDD (from 2018 to 2019). Exclusion criteria were the incompleteness of a patient's records and his/her refusal to attend follow-up sessions.

The data related to each patient, including demographic information, pain severity, functional disability, and patient satisfaction, were recorded by referring to the patients' medical records. All the information has been extracted using medical records and patient interview.

The patients' pain severity was assessed by Numeric Rating Scale (NRS) (0 = no pain, $1-3=$ mild, 4-6= moderate, $7-10=$ severe) before and two years after the treatment. Furthermore, the Oswestry disability index (ODI) measured the patients' disability at the mentioned times using 10 ODI items. Each item was scored from 0-5. High scores indicate high functional disability. ${ }^{11}$

The patients' satisfaction with pain relief was evaluated by question from the patients $(0=\mathrm{bad}, 1=$ moderate, $2=$ good, and 3 =excellent). In case of complications, the type of complication was also recorded.

The data were then coded and entered into SPSS version 19. After examining the normal distribution of quantitative data by the Kolmogorov-Smirnov test, the quantitative variables were compared using the t-test, Mann-Whitney test, repeated measures ANOVA, and paired $t$ test and the qualitative variables were evaluated by the chi-square test. $P<0.05$ was considered statistically significant.

\section{Results}

The mean age of the patients was $49.8 \pm 16.7$ (years). 24 $(60 \%)$ of the patients were women and $16(40 \%)$ men. The duration of symptoms onset was $3.5 \pm 2.3$ (years). Table 1 compares the demographic and radiographic diagnostic data of the patients by sex.

The frequency of disc protrusion levels in the patients studied is shown in Figure 1. The frequency of surgical intervention needs within two years after the intervention is provided in Figure 2.

Drug intolerance, cigarette and alcohol abuse, reflex 
Table 1. The Comparison of the Demographic and Radiographic Diagnostic Information Between the 2 Groups

\begin{tabular}{|c|c|c|c|c|}
\hline & & $\begin{array}{c}\text { Men } \\
(n=16)\end{array}$ & $\begin{array}{l}\text { Women } \\
(n=24)\end{array}$ & $P$ Value \\
\hline \multicolumn{2}{|l|}{ Age (y) } & $42.1 \pm 14.2$ & $54.9 \pm 16.6$ & 0.016 \\
\hline \multicolumn{2}{|l|}{$\mathrm{BMI}\left(\mathrm{kg} / \mathrm{m}^{2}\right)$} & $27.3 \pm 5.2$ & $25.8 \pm 2.3$ & 0.836 \\
\hline \multicolumn{2}{|c|}{ Duration of symptoms onset (y) } & $2.9 \pm 2.3$ & $3.9 \pm 2.3$ & 0.079 \\
\hline \multirow{3}{*}{ Occupation } & Employee & $8(50.0 \%)$ & $4(16.7 \%)$ & \multirow{3}{*}{0.0001} \\
\hline & Housewife & $0(0.0 \%)$ & $20(83.3 \%)$ & \\
\hline & Self-employment & $8(50.0 \%)$ & $0(0.0 \%)$ & \\
\hline \multirow{2}{*}{$\begin{array}{l}\text { History of taking } \\
\text { analgesic drugs }\end{array}$} & Yes & $10(62.5 \%)$ & $15(62.5 \%)$ & \multirow{2}{*}{1.0} \\
\hline & No & $6(37.5 \%)$ & $9(37.5 \%)$ & \\
\hline \multirow{9}{*}{$\begin{array}{l}\text { Disc protrusion } \\
\text { levels }\end{array}$} & L3-5 & $4(25.0 \%)$ & $3(12.5 \%)$ & \multirow{9}{*}{0.4} \\
\hline & L4-5 & $1(6.3 \%)$ & $5(20.8 \%)$ & \\
\hline & L4-S1 & $5(31.3 \%)$ & $10(41.7 \%)$ & \\
\hline & L2-4 & $0(0.0 \%)$ & $1(4.2 \%)$ & \\
\hline & L2-3, L4-5 & $0(0.0 \%)$ & $1(4.2 \%)$ & \\
\hline & L3-S1 & $1(6.3 \%)$ & $0(0.0 \%)$ & \\
\hline & L5-S1 & $4(25.0 \%)$ & $3(12.5 \%)$ & \\
\hline & L1-5 & $1(6.3 \%)$ & $0(0.0 \%)$ & \\
\hline & L2-3, L4-S1 & $0(0.0 \%)$ & $1(4.2 \%)$ & \\
\hline
\end{tabular}

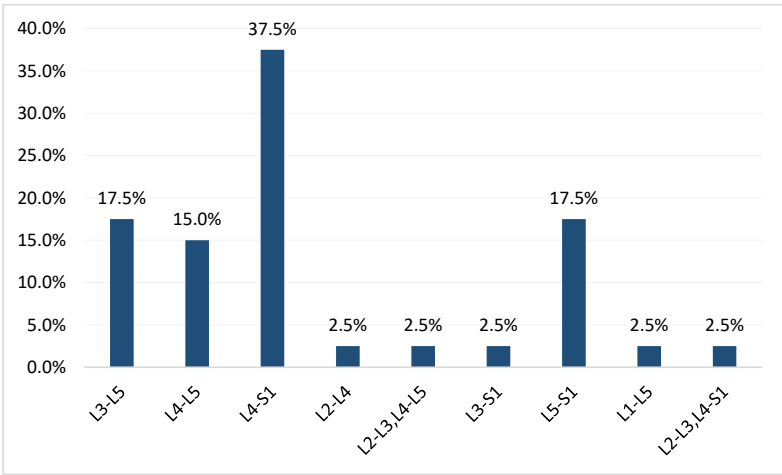

Figure 1. The Percentage Frequency Distribution of Disc Protrusion Levels in the Studied Patients.

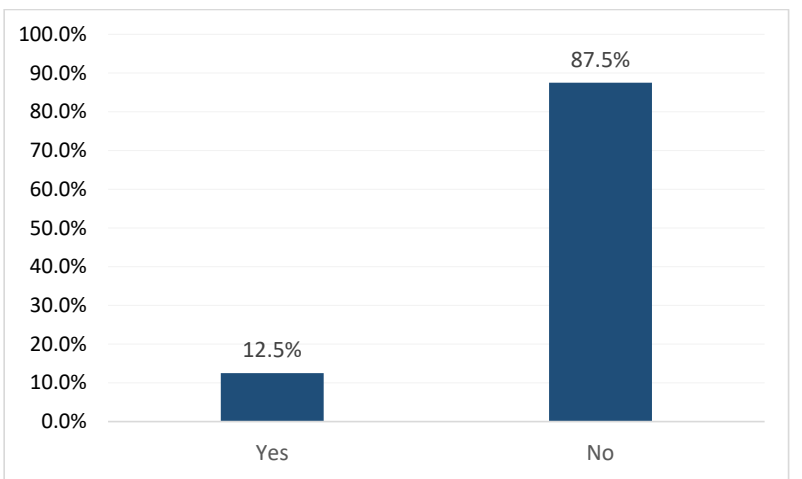

Figure 2. The Frequency Distribution of Surgical Intervention Needs During the 2 Years After the Intervention. deficits, muscle weakness, paresthesia, and the family history of a disc protrusion were not reported in the patients.

Comparing the patients' mean pain scores based on NRS before $(8.1 \pm 1.5)$ and after $(5.3 \pm 3.1)$ carrying out PLDD indicates a statistically significant decrease in the pain severity after the intervention $(P=0.0001)$.

Comparing the patients' mean scores of disability based on ODI before $(32.05 \pm 6.04)$ and after $(21.8 \pm 10.8)$ PLDD shows a statistically significant decrease after the intervention $(P=0.0001)$.

Changes in the NRS score at different times in the three different BMI groups are shown in Figure 3A. These changes do not indicate any statistically significant differences $(P=0.306)$. Changes in ODI scores at different times in the three different BMI groups are shown in Figure 3B. These changes do not demonstrate any statistically significant differences $(P=0.324)$.

Changes in the NRS and ODI scores at different times in different age groups ( $>40$ and $<40$ years old) are shown in Figures $4 \mathrm{~A}$ and $4 \mathrm{~B}$. They demonstrate statistically significant differences decreases in the NRS score
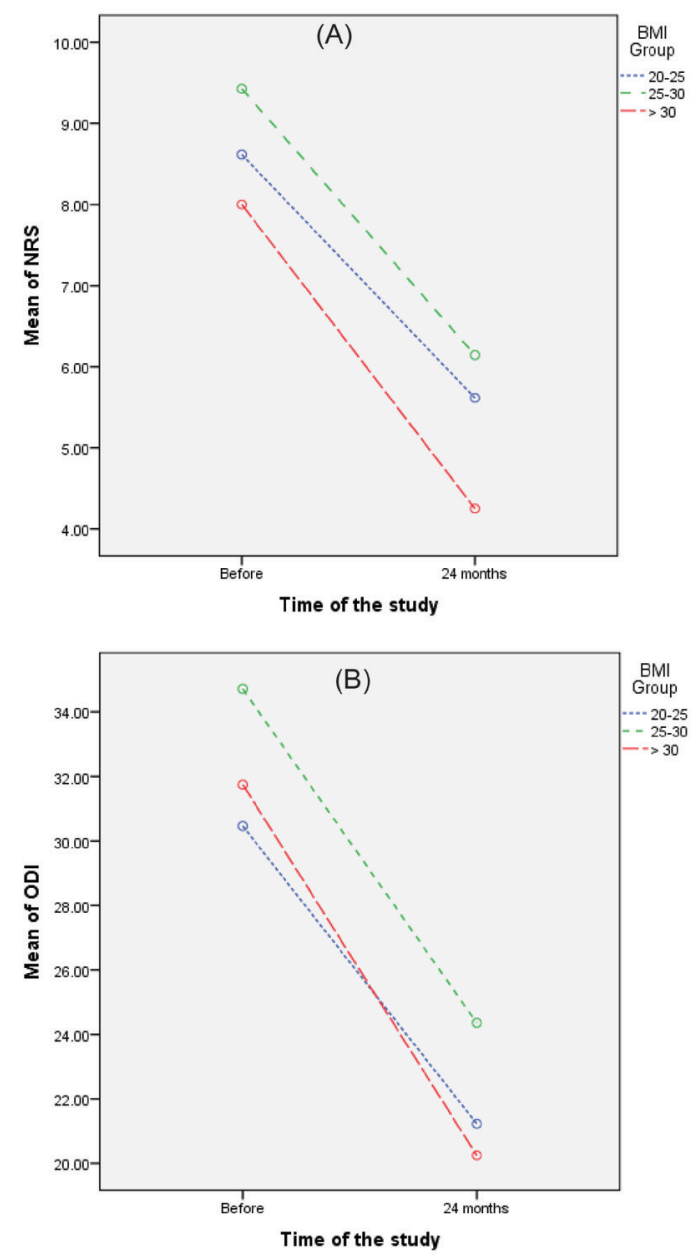

Figure 3. The Comparison of the Changes in the (A) Pain Levels and (B) the ODI Between the 3 Different BMI Groups at Different Times. 

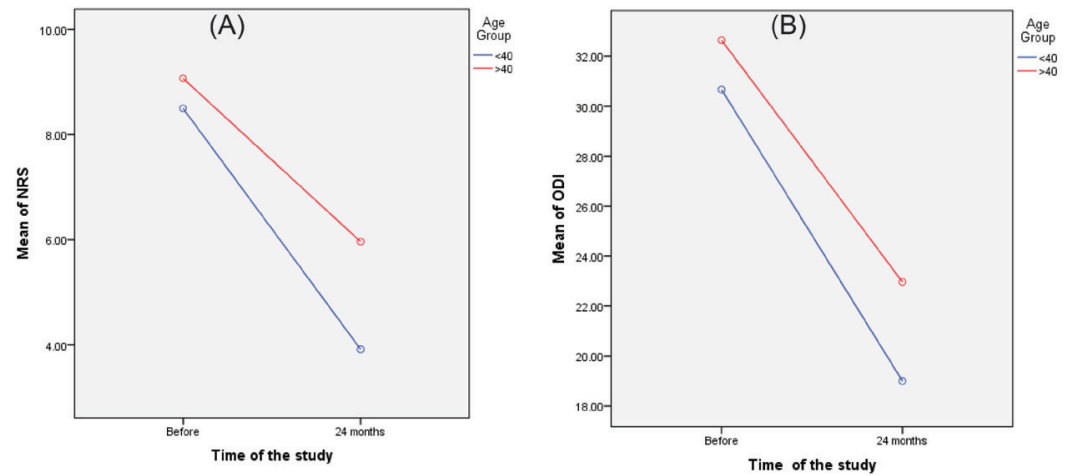

Figure 4. The Comparison of the Changes in (A) the NRS Score and (B) the ODI Score Between the 2 Different Age Groups at Different Times

$(P=0.046)$ but the ODI score do not demonstrate any statistically significant differences $(P=0.223)$ obtained by the patients younger than 40 years old two years after PLDD.

Comparing the mean pain scores based on NRS in the patients studied by sex before (men: $9.0 \pm 1.4$ vs women: 8.8 $\pm 1.6, P=0.844$ ) and after PLDD (men: $4.8 \pm 3.1$ vs women: $5.7 \pm 3.1, P=0.379$ ) revealed no statistically significant differences in the pain severity between the two groups of men and women.

Comparing the mean ODI scores in the patients studied by sex before (men: $60.05 \pm 13.5$ vs. women: $66.5 \pm 10.7$, $P=0.126$ ) and after PLDD (men: $36.6 \pm 21.6$ Vs. women: $48.2 \pm 20.7, P=0.098$ ), showed no statistically significant differences in the ODI score between the two groups of men and women.

As it is shown in Table 2, Comparing the mean pain severity based on NRS examined by considering the disc involvement levels before and after PLDD indicates no statistically significant differences in the pain severity at different disc involvement levels.

A comparison of the mean ODI score examined by considering the disc involvement levels before and after PLDD is shown in Table 3, which does not show a statistically significant difference in the levels of ODI at different disc involvement levels. None of the patients had a complication related to the procedure.

The frequency of the patients' satisfaction with PLDD outcomes is presented in Figure 5.

\section{Discussion}

In the present study, the long-term therapeutic outcomes of 40 patients who had chronic low back pain caused by disc protrusion and were treated with PLDD were reported. The number of females was higher than males. Moreover, the number of patients over 40 years of age was higher than patients under the age of 40 . The most common sites for two-level PLDD were L4-S1 and L3-L5, and the most common sites for one-level PLDD were L5S1 and L4-L5. The levels of pain and functional disability two years after PLDD showed significant improvements. There was no significant difference in the improvement of pain and disability in different BMI groups. However, the levels of pain and disability significantly improved in patients under the age of 40 . In this study, the need for open surgeries was $12.5 \%$ during the follow-up. None of the patients had a complication related to the procedure. These findings are consistent with the results obtained from some previously carried out studies. ${ }^{10,12}$

The LASER stands for light amplification by stimulated emission of radiation. Clinical PLDD was first performed by Choy and Ascher in Europe in 1986. ${ }^{7}$ The FDA also approved the use of PLDD in the United States in $1991 .^{8}$ Choy reported that the intradiscal YAG laser evoked nucleus pulposus evaporation and reported a clinical success rate of $75 \%$ for PLDD. ${ }^{7}$ Another study conducted on 200 patients with disc herniation reported a clinical success rate of $74 \%$ for PLDD over a 4-year follow-up. ${ }^{13}$ In a study carried out on 12539 patients in the United States,

Table 2. Comparing the Mean NRS Between the Disc Involvement Levels in the Studied Patients

\begin{tabular}{lllllllllll}
\hline & L3-5 & L4-5 & L4-S1 & L2-4 & L2-3, L4-5 & L3-S1 & L5-S1 & L1-5 & L2-3, L4-S1 & $\boldsymbol{P}$ Value \\
\hline Before & $9.4 \pm 1.1$ & $8.2 \pm 2.4$ & $8.5 \pm 1.6$ & $10.0 \pm 0$ & $9.0 \pm 0$ & $10.0 \pm 0$ & $9.3 \pm 1.2$ & $10.0 \pm 0$ & $10.0 \pm 0$ \\
After & $5.6 \pm 4.2$ & $4.0 \pm 2.1$ & $5.7 \pm 3.1$ & $8.0 \pm 0$ & - & $5.0 \pm 0$ & $6.6 \pm 1.9$ & $6.0 \pm 0$ & - \\
\hline
\end{tabular}

Table 3. Comparing the Mean ODI Between the Disc Involvement Levels in the Studied Patients

\begin{tabular}{|c|c|c|c|c|c|c|c|c|c|c|}
\hline & L3-5 & L4-5 & L4-S1 & L2-4 & L2-3, L4-5 & L3-S1 & L5-S1 & L1-5 & L2-3, L4-S1 & $P$ Value \\
\hline Before & $32.0 \pm 6.4$ & $32.7 \pm 4.3$ & $32.7 \pm 7.0$ & $41.0 \pm 0$ & $30.0 \pm 0$ & $38.0 \pm 0$ & $31.0 \pm 3.9$ & $25.0 \pm 0$ & $21.0 \pm 0$ & 0.577 \\
\hline After & $20.7 \pm 9.4$ & $18.5 \pm 6.3$ & $24.0 \pm 13.5$ & $31.0 \pm 0$ & $14.0 \pm 0$ & $17.0 \pm 0$ & $24.4 \pm 8.4$ & $21.0 \pm 0$ & - & 0.161 \\
\hline
\end{tabular}




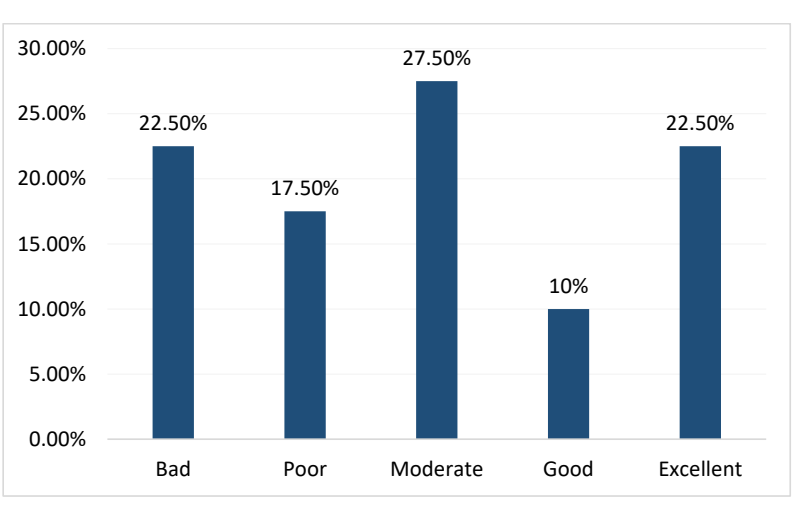

Figure 5. The Frequency of the Patients' Satisfaction With PLDD Treatment Outcomes.

Germany, Italy, France, Russia, Japan, India, South Korea, and Poland over a 23-year follow-up showed that the clinical success rate of PLDD ranged from $70 \%-89 \% .{ }^{14}$ The clinical success rate of PLDD in our study was $87.5 \%$. It seems that the high success rate of PLDD in the current study was due to the proper selection of PLDD candidates and the use of a correct technique and an appropriate laser type and device in the treatment of these patients.

It is well known that different doses of lasers affect cell proliferation, motility, and secretion. ${ }^{15}$

PLDD has recently been used for discogenic pain, radicular pain, lumbar spine stenosis, and lumbar disc herniation. ${ }^{16-19}$

In a study comparing conventional microdiscectomy outcomes with PLDD in patients with disc herniation and radicular pain, it was reported that PLDD outcomes were not superior to surgery. ${ }^{20}$ In another study, favorable therapeutic outcomes were mentioned for the endoscopic percutaneous angioplasty laser used in the treatment of lumbar discogenic pain. ${ }^{21}$ This technique can also be appropriately used in treating thoracic disc herniation. ${ }^{22}$

The use duration and energy requirements in PLDD vary according to the laser wavelength applied in the procedure. ${ }^{19,23}$ Considering the criteria for selecting patients and using adequate conservative treatments before PLDD are important. ${ }^{18,23}$

Based on previously conducted studies, the patient selection criteria for PLDD included leg pain more severe than back pain, disc protrusion without rupture, chronic low back pain for more than three months, failure of noninvasive treatment methods, neurologic deficits, lack of segmental instability, preservation of more than $75 \%$ of disc height, and lack of psychiatric issues. In this study, according to patients' records, these criteria for selecting patients with PLDD were used and satisfactory treatment outcomes were obtained with this technique. Therefore, the criteria for selecting patients are very important for obtaining better therapeutic outcomes. Other studies have shown the short-term and long-term therapeutic effect of PLDD on pain relief in patients with low back pain..$^{23,24-25}$

PLDD has been performed in over 100000 patients worldwide. ${ }^{16}$ In a large series study carried out on 900 patients undergoing percutaneous laser discectomy over a 5-year follow-up, the VAS showed significant improvements and their severe pain was reduced to mild pain. $^{26}$

The limitations of this study were the low sample size and changes in patients' perceptions of their health status, which could influence the evaluation of the impact of the therapeutic interventions.

According to the results obtained, PLDD is a lowinvasive, safe, and effective method that can be used in patients with lumbar disc protrusion and bring about satisfactory therapeutic outcomes by considering the right criteria for selecting patients, appropriate indication, and suitable laser type. This method can be considered as an appropriate choice; however, it cannot be regarded as an alternative to open surgery. In patients with lumbar disc protrusion, PLDD is the second stage of treatment following pharmacological and physical therapies considering the criteria for performing PLDD. Therefore, pain fellowships and neurosurgeons are advised to consider using the PLDD treatment strategy following the treatment protocol of this study. It is recommended that future studies, compared to this study, examine a larger sample size, follow up the subjects for a longer time, and investigate several centers. Moreover, they should compare the outcomes with those of open surgeries and conservative treatments. It is also suggested that a randomized clinical trial be carried out to compare the outcomes of PLDD with conventional surgical procedures.

\section{Conclusion}

It seems that the PLDD is a low-invasive, safe, effective method that can be used in patients with lumbar disc protrusion and bring about satisfactory therapeutic outcomes. Therefore, it can be considered as a suitable choice in treating patients with chronic low back pain caused by a disc protrusion.

\section{Conflict of Interests}

The authors declare no conflict of interest.

\section{Acknowledgment}

This historical cohort study is funded by the vicechancellor for research of Shahid Beheshti University of Medical Sciences. Furthermore, we would like to thank the Research Team for their work in making this study possible.

\section{References}

1. Zileli M, Ozer AF. Perkutan lazer disk dekompresyonu. In: Zileli M, Ozer AF (eds), Omurga ve Omurilik Cerrahisi. Vol: 3. İzmir: İntertıp Yayınevi, 2014: 1751

2. Yucel A. Algologic approaches to the back pain. Turk J Phys Med Rehab. 1998;5(Special issue):1-10. [In Turkish]. 
3. Erdine S. Interventional techniques in pain management. Ankem Derg. 2002;16(3):182-184. [In Turkish].

4. Momenzadeh S, Abbasi M, Ebadifar A,Aryani M, Bayrami J, Nematollahi F. The intravenous laser blood irradiation in chronic pain and fibromyalgia. J Lasers Med Sci. 2015;6(1):6-9.

5. Lee SH, Derby R, Sul DG, Hong JW, Kim GH, Kang $S$, et al. Efficacy of a new navigable percutaneous disc decompression device (L'DISQ) in patients with herniated nucleus pulposus related to radicular pain. Pain Med. 2011;12(3):370-6. doi: 10.1111/j.1526-4637.2011.01064.x.

6. Schenk B, Brouwer PA, van Buchem MAExperimental basis of percutaneous laser disc decompression (PLDD): a review of literature. Lasers Med Sci. 2006;21(4):245-249. doi: 10.1007/s10103-006-0393-y.

7. Choy DS, Case RB, Fielding W, Hughes J, Liebler W, Ascher P. Percutaneous laser nucleolysis of lumbar disks. N Engl J Med. 1987;317(12):771-2. doi: 10.1056/ NEJM198709173171217.

8. Brouwer PA, Peul WC, Brand R, Arts MP, Koes BW, van den Berg AA, van Buchem MA. Effectiveness of percutaneous laser disc decompression versus conventional open discectomy in the treatment of lumbar disc herniation; design of a prospective randomized controlled trial. $B M C$ Musculoskelet Disord. 2009;10:49. doi: 10.1186/1471-247410-49.

9. Schenk B, Brouwer PA, Peul WC, van Buchem MA. Percutaneous laser disk decompression: a review of the literature. AJNR Am J Neuroradiol. 2006;27(1):232-235.

10. Momenzadeh S, Koosha A, Kazempoor Monfared M, Bairami J, Zali A, Ommi D, et al. The effect of percutaneous laser disc decompression on reducing pain and disability in patients with lumbar disc herniation. J Lasers Med Sci. 2019;10(1):29-32. doi: 10.15171/jlms.2019.04.

11. Morcet N, Guggenbuhl P, Rolland Y, Meadeb J, Bousquet C, Veillard E, et al. [Cervical epidural injection technic under computed tomography guidance in the treatment of cervicobrachial neuralgia]. J Radiol. 1999;80(2):161-2. [In French].

12. Erbas YC, Pusat S, Erdogan E. Percutaneous laser disc decompression: Retrospective analysis of 197 cases and review of the literature. Turk Neurosurg. 2015;25(5):766-70. doi: 10.5137/1019-5149.JTN.14692-15.2.

13. Grönemeyer DHW, Buschkamp H, Braun M, Schirp S, Weinsheimer PA, Gevargez A. Image-guided percutaneous laser disk decompression for herniated lumbar disks: A 4-year follow-up in 200 patients. J Clin Laser Med Surg. 2003;21(3):131-138. doi: 10.1089/104454703321895572.

14. Helper S, Slipman CW: Intradiscal therapy. In: Phillips FM, Lauryssen C, editors. The lumbar intervertebral disc. New
York: Thieme; 2010. p. 174-184.

15. Moore P, Ridgway TD, Higbee RG, Howard EW, Lucroy MD. Effect of wavelength on low-intensity laser irradiationstimulated cell proliferation in vitro. Laser Surg Med. 2005;36(1):8-12. doi: 10.1002/lsm.20117.

16. Tassi GP. Comparison of results of 500 microdiscectomies and 500 percutaneous laser disc decompression procedures for lumbar disc herniation. Photomed Laser Surg. 2006;24(6):694-697. doi: 10.1089/pho.2006.24.694.

17. McMillan MR, Patterson PA, Parker V. Percutaneous laser disc decompression for the treatment of discogenic lumbar pain and sciatica: A preliminary report with 3 -month follow-up in a general pain clinic population. Photomed Laser Surg. 2004;22(5): 434-438. doi: 10.1089/ pho.2004.22.434.

18. Black W, Fejos AS, Choy DSJ. Percutaneous laser disc decompression in the treatment of discogenic back pain. Photomed Laser Surg. 2004;22(5):431-433. doi: 10.1089/ pho.2004.22.431.

19. Duarte R, Costa JC. [Percutaneous laser disc decompression for lumbar discogenic radicular pain]. Radiologia. 2012;54(4):336-341. doi: 10.1016/j.rx.2011.02.008.

20. Brouwer PA, Brand R, van den Akker-van Marle ME, Jacobs WCH, Schenk B, van den Berg-Huijsmans AA, et al. Percutaneous laser disc decompression versus conventional microdiscectomy in sciatica: A randomized controlled trial. Spine J. 2015;15(5):857-865. doi: 10.1016/j. spinee.2015.01.020.

21. Lee SH, Kang HS. Percutaneous endoscopic laser annuloplasty for discogenic low back pain. World Neurosurg. 2010;73(3):198-206. doi: 10.1016/j.surneu.2009.01.023.

22. Haufe SMW, Mork AR, Pyne M, Baker RA. Percutaneous laser disc decompression for thoracic disc disease: Report of 10 cases. Int J Med Sci. 2010;7(3):155-159. doi: 10.7150/ ijms.7.155.

23. Knight M, Goswami A. Lumbar percutaneous KTP532 wavelength laser disc decompression and disc ablation in the management of discogenic pain. J Clin Laser Med Surg. 2002;20(1):9-13. doi: 10.1089/104454702753474940.

24. Kim PS. Nucleoplasty. Tech Reg Anesth Pain Manag. 2004;8(1):46-52. doi: 10.1016/j.trap.2003.11.009.

25. Singh V, Manchikanti L, Benyamin RM, Helm S, Hirsch JA. Percutaneous lumbar laser disc decompression: A systematic review of current evidence. Pain Physician. 2009;12(3):573-588.

26. Menchetti PPM, Canero G, Bini W. Percutaneous laser discectomy: Experience and long term follow-up. Acta Neurochir Suppl. 2011;108:117-121. doi: 10.1007/978-3211-99370-5_18. 